\title{
The independence of dynamic spatial orientation from luminance and refractive error
}

\author{
H. W. LEIBOWITZ, C. SHUPERT RODEMER, and J. DICHGANS \\ University of Freiburg, Freiburg im Breisgau, West Germany
}

\begin{abstract}
The effect of refractive error and luminance on circularvection, the illusory sensation of self-motion resulting from rotation of the visual field, was determined. Neither reduction of luminance to levels near absolute scotopic threshold nor induced refractive errors of more than 16 diopters abolished circularvection or influenced any of its latency measures. The results are discussed in terms of the role of the peripheral visual field and the nature of the visual stimulus in ego orientation.
\end{abstract}

A growing body of literature suggests that the central retinal regions are concerned primarily with form perception and object recognition, while the periphery is specialized for visual localization of objects and orientation in space (Held, 1968, 1970, 1971; Ingle, 1967, 1973; Schneider, 1967, 1969; Trevarthen, 1968). Recent research on the visual mediation of the sensation of ego-motion or vection ${ }^{1}$ and stabilization of posture supports this differentiation between central and peripheral vision (Brandt, Dichgans, \& Koenig, 1973; Dichgans \& Brandt, 1974; Held, Dichgans, \& Bauer, 1975; Lestienne, Soechting, \& Berthoz, 1977). Given this functional differentiation of the central and peripheral visual fields, the question arises as to whether these two functions are controlled by different stimulus parameters, such that under ordinary life conditions, visually mediated spatial orientation may be preserved while foveal object recognition and detail discrimination are impaired. Such a dissociation would have important theoretical, clinical, and behavioral consequences.

Two of the most fundamental variables affecting the performance of the visual system are luminance and sharpness of the retinal image. Essentially all of the classical visual functions, such as visual acuity (Shlaer, 1937), flicker, (Hecht \& Verrijp, 1933), stereoscopic depth (Mueller \& Lloyd, 1948), and brightness discrimination (Hecht, Peskin, \& Patt, 1938), as well as reaction time (Teichner \& Krebs, 1972), are very sensitive to luminance, demonstrating a marked improvement in performance with increasing luminance before reach-

Supported by the Deutsche Forschungsgemeinschaft SFB70 (Hirnforschung und Sinnesphysiologie), and Grant MH 08061 from the National Institute of Mental Health. This research was conducted while $H$. Leibowitz was on sabbatical leave from Pennsylvania State University as a Senior Scientist Awardee of the Alexander von Humboldt Foundation. The current address for H. W. Leibowitz and C. Shupert Rodemer is: Moore Building, Pennsylvania State University, University Park, Pennsylvania 16802. The address of J. Dichgans is: Department of Neurology, Liebermeisterstrasse 18-20, D-74 Tübingen, West Germany. ing an asymptote at higher luminance levels. Correspondingly, a large proportion of the psychophysical literature is concerned with the effect of manipulation of luminous energy in the form of luminance level and/or duration of exposure. The effect of refractive error has not been as systematically investigated. However, the fundamental importance of a sharp retinal image is axiomatic in visual science and underlies the efforts of a large part of the visual health care system.

There are a number of indications in this literature that the importance of both luminance level and refractive error is diminished in the peripheral retina. The functions relating resolution (Kerr, 1971) and flicker (Hecht \& Verrijp, 1933) to luminance become progressively independent of luminance as the image falls on more peripheral regions of the retina. Similarly, the importance of refractive error on resolution is reduced with peripheral observation (Millodot, Johnson, Lamont, \& Leibowitz, 1975).

An earlier study by Berthoz, Pavard, \& Young (1975) has suggested that luminance thresholds for linear egomotion sensation (linearvection) are very close to the absolute luminance thresholds for image detection. The present study further analyzes the contribution of luminance in the peripheral control of dynamic spatial orientation and, for the first time, investigates the importance of refractive error on circularvection (CV) which may be considered as paradigmatic for dynamic visual orientation in space.

\section{GENERAL PROCEDURE}

\section{Subjects}

Fourteen college students participated in the first half of Experiment 1 , while 10 participated in the remainder of the study. None was familiar with the phenomena under investigation.

\footnotetext{
Apparatus

The subjects were seated in the center of a rotatable drum with an inner diameter of $1.4 \mathrm{~m}$ and a height of $1.95 \mathrm{~m}$ (manufactured by Tönnies, Freiburg im Breisgau). The interior surface of the drum is covered with vertical, alternating black and white stripes (contrast
} 
$88 \%$ ), each subtending $7.5 \mathrm{deg}$ of arc and illuminated from the ceiling by incandescent light. Luminance can be varied by a calibrated potentiometer. In these studies, the chair always remained stationary.

\section{EXPERIMENT 1}

\section{Procedure}

When the drum was rotating with a velocity of $60 \mathrm{deg} / \mathrm{sec}$, the subject was requested to open his eyes. Under this condition, the subject experiences the following time course of the illusion (Brandt et al., 1973). First, drum motion is reported. After an onset latency of several seconds, this is followed by the sensation of simultaneous deceleration of the drum and a matching acceleration of self-motion. After a few more seconds, the drum appears to stop, and the subject perceives exclusive self-motion or vection in the direction opposite to drum rotation. The latter stage is referred to as "saturation" or full vection. Approximately $30 \mathrm{sec}$ after full vection has been reached, the subject is instructed to close his eyes and typically reports continued feelings of selfrotation, referred to as the "aftereffect." In this study, the dependent variable consisted of the duration of these three stages, i.e., the time to onset of $\mathrm{CV}$, the time from onset to saturation or full vection, and the duration of the aftereffect. These durations were measured since they most probably represent the best indica'tors of the effectiveness of a given CV stimulus (Brandt, Wist, \& Dichgans, 1975; Dichgans \& Brandt, 1978). The procedure was repeated at least twice with right and left rotation of the drum for each luminance level.

Three levels of luminance (white stripes) were employed, $\log 1.22$, $\log -1.29$, and for the lowest luminance level, between $\log -3.61$ and $\log -2.68 \mathrm{~cd} / \mathrm{m}^{2}$. The first two levels were photopic and the third scotopic. The scotopic level was tested after $10 \mathrm{~min}$ of dark adaptation, after which the luminance level in the drum was slowly increased until the subject could clearly experience CV. The luminance level at which the pattern was first seen was also determined. This threshold demonstrated intersubject variability.

In a preliminary study, it was determined that large refractive errors, induced by having the subject wear positive spherical lenses, had no effect on CV latencies. For this reason, only the maximum refractive error was introduced for comparison with normal vision. This was induced by 20 -diopter positive spherical lenses mounted in a standard spectacle frame. Positive lenses also increased retinal image speed, but within the velocity range employed in this study, latencies have been shown to be independent of speed (Brandt, Dichgans, \& Koenig, 1973).

In order to be certain that no peripheral stimulation was possible around the edges of the frames, a black cloth mask was fitted around the frames so that the drum was visible only through the lenses. As a control, the subjects also observed at the highest illumination level through optical blanks and standard frames with the black cloth mask. Finally, refractive error was combined with the three luminance tests and, again, at least two trials were made under both left and right rotation of the drum under each condition.

\section{Results}

CV was invariably experienced, even with the lowest luminance and the highest refractive error tested, and was saturated. Latency differences between left and right motion, which are typically observed in vection studies, could be attributed to order effects. The latencies for the various conditions of the main experiment are presented in Figure 1. It will be noted that with unrestricted vision (A, B, and $C$ ), the variations as a function of luminance level (A highest, C lowest) are small, particularly in comparison with typical foveal functions. With lowered luminance level, the time to the beginning of

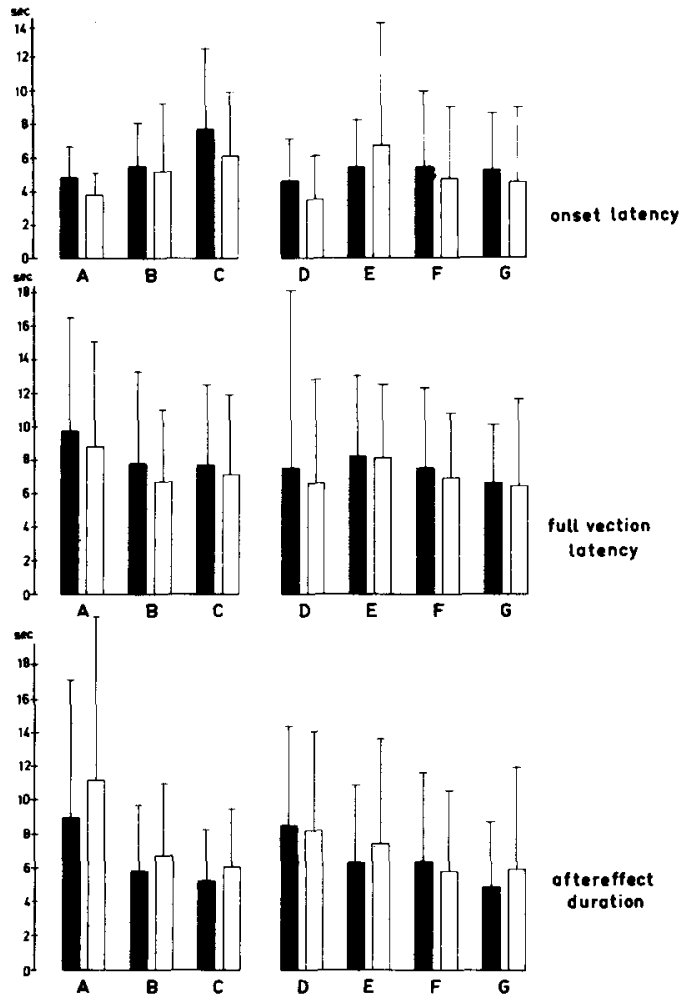

Figure 1. Mean duration of the indicated dependent measures. $A, B$, and $C$, unrestricted vision; $D$, blank spectacle frames; $E, F$, and $G$, spectacle frames with 20-diopter positive lenses. For $A, D$, and $E$, luminance level was photopic, for $B$ and $F$, low photopic, and for $C$ and $G$, scotopic. Bars indicate one standard deviation.

vection increases slightly, the time to full vection decreases, and the duration of the aftereffect decreases from the highest to the lowest luminance level (A vs. C). These differences are small in relation to the variability. Column D in Figure 1 presents the data obtained with blank spectacle frames and the highest luminance, and $E, F$, and $G$ represent those obtained with 20-diopter positive lenses mounted in the same type of frames at the same luminance levels used previously ( $E$, highest luminance; $G$, lowest). Since the radius of the drum is $9.7 \mathrm{~m}$, one would expect a normal accommodative effort of 1.4 diopters. Observation through a 20-diopter positive sphere, consequently, would introduce a refractive error of 18.6 diopters, of which at the most, 1 or 2 diopters could be overcome by negative accommodation, resulting in a refractive error of more than 16 diopters. This is, indeed, a large refractive error, particularly when one considers that, normally, errors of .25 or .50 diopter are corrected in clinical practice, and that an uncorrectable error of 2.5-3.0 diopters corresponds to legal blindness in the U.S.A. (Borish, 1970) or an acuity worse than $20 / 200$. In spite of this severe blur, there is strikingly little difference among the values for the three measures of the circularvection effect in comparison with unrestricted vision. ${ }^{2}$ In 
particular, it should be noted that the values for the lowest luminance level, which is very close to the absolute visual threshold, together with the severe refractive error $(G)$, produces $C V$ values for all three measures which are similar to those for the other experimental conditions of this study. The small difference in onset latency seen between Conditions $A$ and $C$ is not seen between Conditions $E$ and $G$ although, with the latter, not only luminance, but also refraction has been degraded. In general, the differences as a function of luminance level, refractive error, or both, are conspicuous by their insignificance.

\section{EXPERIMENT 2}

\section{Procedure}

The wide range of luminance values over which the measures of circularvection show essentially the same values (in this experiment, over a range of almost $5 \mathrm{log}$ units) is a rare finding in visual psychophysics. It would appear that when the vection effect is activated, further increase in luminance has essentially no influence on the latency measures.

More than likely, if the luminance level could have been increased beyond the maximum available in this apparatus, no further changes would have been observed. However, this is not necessarily true for the low end of the luminance continuum. A question remains as to whether circularvection could be elicited at luminance levels below those used in the first part of the experiment. Consequently, 10 of the subjects who had served in the first part of the study were retested with unrestricted vision at different luminance levels near absolute threshold. After a full $1 / 2 \mathrm{~h}$ of adaptation in total darkness, the luminance level in the drum was slowly increased until the subject reported being able to distinguish the objectively stationary black and white stripe pattern. Using the same criteria for the moving drum, the subjects were asked to qualitatively report the occurrence of the selfmotion sensation, full vection, and the presence and duration of the aftereffect. For those subjects who did not experience all the criteria of "normal" circularvection at this luminance level, luminance was increased gradually and the procedure repeated until "normal" circularvection occurred. The luminance level was then decreased in the same manner until the subject could no longer detect the contrast pattern. Two trials under both left and right rotation of the drum were made at each luminance level.

\section{Results}

Only at extremely low luminance levels and after 30 min of dark adaptation, a faint impression of drum motion may be discernible while $\mathrm{CV}$ is totally absent $(-,-,-)$. Incomplete ego-motion may be perceived without saturation $(+,-,-)$ or full saturated $\mathrm{CV}$ may be reported without any aftereffect $(+,+,-)$. With a slight increase in luminance, normal saturated $\mathrm{CV}$ with aftereffect was perceived in all cases $(+,+,+)$.

The data for the individual subjects are tabulated in Table 1. For some subjects, normal circularvection was obtained as soon as the stripes were visible. For others, there is a small, no more than .5 log unit ( at a level of approximately $-4.0 \mathrm{log}$ units), difference between the perception of stripes and normal vection responses. These subjects were recalled for a second testing under the same conditions, and all showed a normal vection pattern as soon as the stripes were visible.

\section{DISCUSSION}

The data of the present study demonstrate that there is essentially no relationship between luminance level of refractive error and the time to onset of circularvection, the time to full saturation, or the duration of the aftereffect. Berthoz et al. (1975) have previously reported that the luminance thresholds for linearvection are very close to the absolute luminance thresholds for image detection. The present results extend their findings to include circularvection as well. The small difference between the absolute luminance threshold for the stationary stripes and the appearance of $\mathrm{CV}$ is a transitory phenomenon which disappears quickly with minimal practice. ${ }^{3}$

The independence of circularvection from refractive error is a new and striking finding. Although it has been reported that correction of the refractive error which is normally present in the periphery

Table 1

Circularvection Parameters; Self-Motion Sensation, Full Vection or Saturation and Aftereffect, at Low Scotopic Luminance Levels $\left(\log \mathrm{cd} / \mathrm{m}^{2}\right)$ Following $1 / 2 \mathrm{~h}$ of Dark Adaptation

\begin{tabular}{|c|c|c|c|c|c|c|c|c|c|c|}
\hline \multirow{2}{*}{$\begin{array}{l}\text { Luminance } \\
\text { Level }\end{array}$} & \multicolumn{10}{|c|}{ Subjects } \\
\hline & S.S. & C.R. & U.K. & D.K. & J.W. & F.T. & J.M. & S.M. & E.B. & T.B. \\
\hline-3.59 & & & & & & & & +++ & & \\
\hline-3.64 & & & & & & & $++t$ & +-+ & & $t+t$ \\
\hline-3.72 & & & & & & & $+-t$ & $+\ldots+t$ & & +-+ \\
\hline-4.00 & & & & & & & +-+ & $+-t$ & $+t+$ & +-- \\
\hline-3.89 & & & & $++t$ & & $+t+$ & +-- & +-- & ++- & +-- \\
\hline-3.99 & & ++ & & $+-t$ & +++ & $+-t$ & -- & --- & +-- & -- \\
\hline-4.05 & $++t$ & $+-t$ & +++ & -- & +-- & & & --- & +-- & \\
\hline-4.14 & $+\ldots+$ & +-- & $+\ldots+$ & & & & & & +-- & \\
\hline-4.20 & --- & --- & +-- & & & & & & & \\
\hline-4.29 & & & & & & & & & & \\
\hline-4.37 & & & & & & & & & & \\
\hline
\end{tabular}

Note-Luminance level was increased until a positive response was obtained for all three parameters. 
does not influence static visual resolution (Millodot et al., 1975), correction of such "normal" refractive errors may have a beneficial effect on the threshold detection of motion (Johnson \& Leibowitz, 1974; Leibowitz, Johnson, \& Isabelle, 1972). However, the level of the blur produced by these normally occurring errors is small in relation to that employed in the present study. Thus, the independence of circularvection and severe blur represents a unique phenomenon in visual psychophysics. This may possibly be explained by the very large receptive fields involved in peripheral motion perception, particularly with the low spatial-frequency pattern employed in the present apparatus $(.067$ cycle/deg). It appears as if the system needs only extremely shallow luminance gradients in order to react to displacement, at least at rather high velocities. The insensitivity of the orientation and localization mechanisms (ambient vision) to retinal image blur and luminance contrasts sharply with the dependence of foveal (focal) vision on these same variables. The similarity of pattern motion-detection thresholds and vision induced ego-motion sensation thresholds may reflect properties of a common distal pathway.

The biological significance of these results is clear. It is important to maintain body posture and dynamic spatial orientation over the complete functional range of luminance. The dependence of orientation and localization mechanisms from luminance level permits the system to operate efficiently over the dynamic luminance range of visual stimulation. ${ }^{4}$ The dependence of the system from peripheral refractive error is also of functional significance. In humans, large variable refractive errors may be present in the periphery even though there is no refractive error in foveal vision. Such errors are highly variable among subjects and may be different in various meridians for the same subject (Ferree \& Rand, 1933). The insensitivity of the ego-orientation system to retinal image blur permits the full participation of peripheral vision in postural stabilization (Dichgans, Mauritz, Allum, \& Brandt, 1976) and orientation in space independent of differences in resolving power.

\section{REFERENCES}

Berthoz, A., Pavard, B., \& Young, L. R. Perception of linear horizontal self-motion induced by peripheral vision (linearvection): Basic characteristics and visual-vestibular interactions. Experimental Brain Research, 1975, 23, 471-489.

Borish, I. Clinical refraction (3rd ed.). Chicago: Professional Press, 1970.

Brandt, T., Dichgans, J., \& Koenig, E. Differential effects of central versus peripheral vision on egocentric and exocentric motion perception. Experimental Brain Research, 1973, 16, 476-491.

Brandt, T., Wist, E. R., \& Dichgans, J. Optisch induzierte Pseudocoriolis Effekte und Circularvektion. Ein Beitrag zur optisch-vestibulären Interaktion. Archiv fur Psychiatrie und Nervenkrankheiten, 1971, 214, 365-389.
Brandt, T., Wist, E. R., \& Dichgans, J. Foreground and background in dynamic spatial orientation. Perception \& Psychophysics, 1975, 17, 497-503.

DichgaNs, J. Optokinetic nystagmus as dependent on the retinal periphery via the vestibular nucleus. In $\mathrm{R}$. Baker \& A. Berthos (Eds.), Control of gaze by brain stem neurons. Developments in Neuroscience (Vol. 1). Elsevier: North-Holland Biomedical Press, 1977.

Dichgans, J., \& Brandt, T. The psychophysics of visuallyinduced perception of self-motion. In F. O. Schmidt \& F. G. Worden (Eds.), The neurosciences: Third study program. Cambridge, Massachusetts: M.I.T. Press, 1974.

Dichgans, J., \& BrandT, T. Visual-vestibular interaction: Effects on self-motion perception and postural control. In R. Held, H. Leibowitz, \& H. L. Teuber (Eds.), Handbook of sensory physiology (Vol. VIII), Perception. Heidelberg: Springer, 1978.

Dichgans, J., Mauritz, K. H., Allum, J. H. J., \& Brandt, T. Postural sway in normals and ataxic patients: Analysis of the stabilizing effects of vision. Aggresologie, 1976, 17, 15-24.

FERREE, C. W., \& RAND, G. Interpretation of refractive conditions in the peripheral field of vision. A.M.A. Archives of Ophthalmology, 1933, 9, 925-938.

Fischer, M. H., \& KORNMÜlLER, A. E. Optokinetisch ausgelöste Bewegungswahrnehmung und optokinetischer Nystagmus. Journal fur Psychologie und Neurologie, 1930, 41, 273-308.

Hecht, S., Peskin, J. C., \& Patt, M. Intensity discrimination in the human eye, II. Relationship between $\Delta I / I$ and intensity for different parts of the spectrum. Joumal of General Physiology, 1938, 22, 7-19.

HeCht, S., \& VerRIJP, C. D. Intermittent stimulation by light: III. The relationship between intensity and critical fusion frequency for different retinal locations. Journal of General Physiology, 1933, 17, 251-265.

HELD, R. Dissociation of visual functions by deprivation and rearrangement. Psychologische Forschung, 1968, 31, 338-348.

HELD, R. Two modes of processing spatially distributed visual stimulation. In F. O. Schmidt (Ed.), The neurosciences: Second study program. New York: Rockefeller University Press, 1970.

HeLd, R. Vision and movement. In J. R. Pierce \& J. R. Levene (Eds.), Visual sciences. Bloomington, Indiana: Indiana University Press, 1971.

Held, R., Dichgans, J., \& Bauer, J. Characteristics of moving visual scenes influencing spatial orientation. Vision Research, $1975,15,357-365$.

INGLE, D. Two visual mechanisms underlying the behavior of fish. Psychologische Forschung, 1967, 31, 44-51.

INGLE, D. Two visual systems in the frog. Science, 1973, 181, 1053-1055.

Johnson, C., \& Leibowitz, H. W. Practice, refractive error and feedback as factors influencing peripheral motion thresholds. Perception \& Psychophysics, 1974, 15, 276-280.

KERR, J. L. Visual resolution in the periphery. Perception \& Psychophysics, 1971, 9, 375-378.

Leibowitz, H. W., Johnson, C. A., \& Isabelle, E. Peripheral motion detection and refractive error. Science, 1972, 177, 1207-1208.

LEIBOwITZ, H., \& OwEns, D. A. Nighttime driving accidents and selective visual degradation. Science, 1977, 197, 422-423.

Lestienne, F., Soechtina, J., \& Berthoz, A. Postural readjustments induced by linear motion of visual scenes. Experimental Brain Research, 1977, 28, 363-384.

MACH, E. Grundlinien der Lehre von den Bewegungsempfindungen. Leipzig: Englemann, 1875.

Millodot, M., Johnson, C. A., LAMont, A., \& Leibowitz, H. W. Effects of dioptrics on peripheral visual acuity. Vision Research, 1975, 15, 1357-1362.

Mueller, C. G., \& LloYD. V. L. Stereoscopic acuity for various levels of illumination. Proceedings of the National Academy of Sciences, 1948, 34, 223-227.

SCHNEIDER, G. E. Contrasting visuomotor functions of tectum and cortex in the golden hamster. Psychologische Forschung, 1967, $31,52-62$. 
SChNeider, G. E. Two visual systems. Science, 1969, 163, 895-902.

SHLAER, S. The relation between visual acuity and illumination. Journal of General Physiology, 1937, 21, 165-188.

Teichner, W. H., \& Krebs, M. Laws of the simple visual reaction time. Psychological Review, 1972, 79, 344-358.

Trevarthen, C. B. Two mechanisms of vision in primates. Psychologische Forschung, 1968, 31, 299-337.

\section{NOTES}

1. Vection (Fischer \& Kornmüller, 1930), or the perception of self-movement, is the illusory feeling of motion which accompanies displacement of a large portion of the visual field, such as when a train on an adjacent track is moving and this is erroneously perceived as self-motion by the observer (Mach, 1875). Circularvection (CV) refers to the compelling impression of rotary self-motion which occurs when a surrounding cylinder is rotated about an actually stationary object. Under such conditions, the subject reports a realistic and compelling feeling of self-motion while the walls of the cylinder appear to remain stationary (Brandt, Wist, \& Dichgans, 1971; Brandt, Dichgans, \& Koenig, 1973; Dichgans \& Brandt, 1978).

2. The independence of $\mathrm{CV}$ from refractive error is not necessarily inconsistent with the observation that the peripheral objectmotion detection-velocity thresholds are sensitive to retinal blur
(Johnson \& Leibowitz, 1974; Leibowitz, et al., 1972). In the present experiment, $\mathrm{CV}$ results from a suprathreshold stimulus moving at velocities roughly 250 times faster than required for threshold detection. Undoubtedly, the change in luminance per unit time is critical, but within the range of rapid velocities encountered under behavioral conditions, blur has a surprisingly small effect.

3. In a recent study, we have determined that for a small $\left(15^{\circ}\right.$ wide $\times 2^{\circ}$ high) centrally fixated field, optokinetic nystagmus (OKN) with normal gain may be elicited as long as the moving blur pattern can be resolved. Such a small field does not elicit CV under any conditions and therefore presumably does not stimulate the subcortical OKN mechanism (Dichgans, 1977). When the pattern can be resolved, cortical OKN from the central visual field and $\mathrm{CV}$ from the periphery are elicitable.

4. The functional degradation of the central retina at low luminance levels along with the persistence of a high level of efficiency of the retinal periphery can result in a hazardous situation while operating a vehicle under low luminance levels. In this case, steering ability guided by the periphery-dependent orientation mechanisms is unaffected, resulting in a high level of selfconfidence, while the ability to detect or recognize centrally fixated stimuli is impaired (Leibowitz \& Owens, 1977).

(Received for publication September 6, 1978; revision accepted November 24,1978 .) 